From Making Futures by Pelle Ehn, Elisabet M. Nilsson, and Richard Topgaard (eds.)-MIT Press, 2014. CC:BY-NC.

http://mitpress.mit.edu/books/making-futures

\title{
4 Connecting with the Powerful Strangers: From Governance to Agonistic Design Things
}

\author{
Anders Emilson and Per-Anders Hillgren
}

Social innovation involves-indeed, requires-redistributing power. It's well and good to talk about curing diseases, supporting social innovation, changing poor neighbourhoods, improving education, stimulating economic development, sustaining the environment-but changing the distribution of power? Why would those with wealth and power want to support that?

Frances Westley, Brenda Zimmerman, and Michael Quinn Patton, Getting to Maybe $(2007,121)$

It is afternoon in Malmö's city hall. We are two design researchers, waiting outside a meeting room to make a presentation of what we can offer in the process of exploring what an incubator for social innovation in Malmö can be. We will meet with a group of civil servants responsible for trade, industry, and economic growth. The door opens and a man exits, having finished his presentation. Later we will realize that we have just met one of the "powerful strangers" - actors with "larger portions of money, authority and access" (Westley, Zimmerman, and Patton 2007, 99)—who will have major roles in what eventually will become an "incubator for new jobs" under the name Growth Malmö. We enter the room and make our presentation. Among other things, we say that we have good connections with innovative grassroots organizations. One of the civil servants replies "We need that!"

The rather trivial response "We need that!" summarizes why people collaborate: they lack something that someone else has. It is also a fact that today, more than in the past, an organization has to collaborate with other organizations to get access to resources (knowledge and skills) it needs if it is to be innovative (Lakhani and Panetta 2007; Lusch, Vargo, and Tanniru 2010). Collaboration is also the "underlying ethic" of social innovation (Mulgan 2012, 61). That was one reason why, when Malmö Living Lab the Neighborhood got the commission from the municipality to run a series of workshops to explore what kind of support structures and functions an incubator for social innovation could have, we gathered a rather diverse group of people representing the private sector, the public sector, and the third sector, as well as academia. In the workshops, knowledge, experiences, and values were shared, but there also was 
some confrontation. The other reason we wanted to gather a diverse group of actors was purely democratic. An incubator aimed at social innovation and the improvement of well-being of all inhabitants in Malmö is something that concerns everybody, and therefore a wide perspective of people should be able to make their opinions heard, to define issues, and to contribute ideas.

This chapter will tell the story of the incubator process in relation to local democracy and emerging initiatives of social innovation in Malmö, the third most populous city in Sweden. Malmö has a reputation as a world leader in environmental sustainability, but it is struggling with growing social inequalities, child poverty, unemployment, and violence. To meet these challenges and to achieve a balance between all three aspects of sustainability - the social, the environmental, and the economic — the municipality of Malmö has launched two projects: the Områdesprogram för ett socialt hållbart Malmö (Area Programs for a Socially Sustainable Malmö and the Kommissionen för ett socialt hållbart Malmö (Commission for a Socially Sustainable Malmö).

The Area Programs is a five-year project with the objective of improving living conditions, security, and job opportunities in five low-income areas in Malmö. Involving citizens and creating innovations is fundamental to the work of the Area Programs. The idea of an incubator came from a civil servant responsible for the Area Programs who saw the need for a clearer structure for innovative work.

The final report of the Malmö Commission calls for knowledge alliances, meaning "equal collaborations between researchers and stakeholders from, for example, administration, associations, and trade and industry" (Stigendal and Östergren 2013, 131; translated from Swedish). But, as this chapter will make clear, such alliances easily fail or fall apart if already powerful actors refuse to take part and refuse to let go of power, resources, and control. Instead of yielding new alliances, new knowledge, and social innovations, the whole project slips back to business as usual and undemocratic processes. However, if the goals are to produce social innovation and to tackle complex challenges such as sustainability, it will be necessary to explore different proposals for how to constitute knowledge alliances and new democratic platforms. Two things that are central to this story are the concept of governance and the fact that political processes now are carried out by informal governance networks that most often consist of "coalitions of economic, socio-cultural or political élites" (Swyngedouw 2005, 1999). Many researchers describe these governance networks as undemocratic. For that reason, there is a need to strengthen the democratic aspect by means of new forms of participation and democratic platforms (Stigendal 2011).

In this chapter we will discuss how local democracy and informal governance networks may be influenced by recent developments in participatory design such as "design things" (Ehn 2008; Binder et al. 2011; Björgvinsson, Ehn, and Hillgren 2010, 2012a), "infrastructuring," and "agonism" (Björgvinsson, Ehn, and Hillgren 2010, 2012a). We will focus on the notion of "agonistic design things" and on whether an 
agonistic design thing can be a kind of extended knowledge alliance that can include more heterogeneous actors and, consequently, their knowledge and their experiences. We will also argue that an agonistic design thing might be of relevance when engaging in social innovation, and that this requires redistributing power and resources (Westley, Zimmerman, and Patton 2007).

The incubator process consisted of two phases: (1) the workshop series at the university, led by Living Lab the Neighborhood, and (2) the preparation and writing of the decision document for the politicians at the municipality's Trade and Industry Agency. Two types of networks have been active in producing the outcome: (1) the workshop network (with the character of a design thing) and (2) the trade and industry network (with the character of an informal governance network). The only connection between these phases and networks was the written report from Living Lab the Neighborhood (Ehn et al. 2011) and three participants in the workshops. In the transition and translation between these phases and networks, the object of design-the incubator for social innovation-vanished.

\section{Governance and accountability}

The concept of governance has got a lot of attention in political theory in recent years and can be seen both as an analytical framework and as a phenomenon. Although the definition of 'governance' has been debated, most often the emphasis is on the idea that a significant part of politics takes place, not within formal governmental institutions, but rather in partnerships with non-governmental actors (Pierre and Peters 2000). One of the more influential contributors to governance theory, Rod Rhodes (1997), has argued that governance is performed mainly through informal self-organized networks, stretching between the public and private sectors. Governance can be seen as a process of "hollowing out the state" whereby privatization of services has increased at the expense of the public sector, which has become smaller and fragmented (ibid.). It can also be seen as the state's ability to adapt to rapid external changes and to find new approaches to steering society in a world where complexity evolves and challenges go beyond what the state alone can solve (Pierre and Peters 2000).

Whatever perspective on governance you choose, it also poses some challenges regarding political accountability. When politics is made in informal networks, one of the consequences is that the boundaries between public and private become blurred, which leads to a blurring of responsibilities and accountability (Stoker 2000). This is not necessarily intentional, but the complexity of the networks makes it difficult for average citizens to understand who is accountable for what or to understand how responsibilities are divided (Pierre and Peters 2000). Finally, and highly relevant from a participatory design perspective, if political power is exercised through informal networks, some actors will always be excluded from these networks (Stoker 2000). 


\section{City politics and the political landscape in Malmö}

To better understand the role of governance networks in the local context, we turn to the political scientist Tove Dannestam. In her dissertation she examines the political landscape in Malmö and reveals that a significant part of the political processes in the city is executed through informal networks including important key representatives from the business sector and leading civil servants and politicians. According to Dannestam (2009), decisions and consensus are often settled in the corridors before they enter into more public political forums. This has two important implications. One is that it provides the people in these networks with the "ability to act", which make them vigorous and efficient. Dannestam (ibid., 189; translated from Swedish) presents transcripts of interviews in which this becomes evident-for example, the city's former planning director says "In the city of Malmö you can get things done." The same former planning director also argues that these informal networks have evolved and are important because the "municipality's traditional vertical division between units can be paralyzing." However as Dannestam (ibid., translated from Swedish) states, this has some implications for democracy: "On one side you have efficiency and the ability to act, on the other side you have the democratic aspects of planning which tends to be a slow process." Dannestam also describes how these informal governance networks, both in Malmö and other cities around the world, are relevant to what is called "city politics." If the concern of traditional local politics was how to implement welfare services, the aim of city politics is to increase local economic growth and brand cities as attractive, attractiveness being defined mostly from a business perspective. Dannestam writes that city politics have been in favor of the trade and industry's interests and their influence on local politics. Through city politics, a market-economy orientation has been established in the public administration. Another consequence of city politics and governance is that issues that in traditional government were characterized by political conflict are now described as a neutral

development in everyone's interest. This consensus between a limited network of actors is considered problematic from a democratic perspective by many researchers. Mikael Stigendal (2011) cites Claude Jaquier's assertion that this consensus hides fundamental conflicts and therefore the democratic aspect needs to be strengthened through new forms of participation.

\section{Networks and social innovation}

The kind of networks and resources that are considered to be valuable in social innovation differ sharply from the small, informal, and exclusive governance networks that have been described above. One reason is that social innovation is not limited to market-oriented entrepreneurship, which is favored in governance and city politics. Westley 
and Antadze (2010, 3) claim that social innovation "does not necessarily involve a commercial interest, though it does not preclude such interest," and that "more definitively, social innovation is oriented towards making a change at the systemic level."

In social innovation theory, the ultimate goal of such innovation is often described as systemic change (Murray, Caulier-Grice, and Mulgan, 2010; Nicholls and Murdock 2012; Westley and Antadze 2010). This disruptive level of social innovation (see chapter 2 in this volume and page 4 of Nicholls and Murdock 2012) involves interaction between diverse elements such as social movements, business models, laws, and new practices (Murray, Caulier-Grice, and Mulgan 2010). Systemic innovation "commonly involves changes in public sector, private sector, grant economy and household sector, usually over long periods of time" (ibid., 13).

Disruptive social innovation will not be content with relieving the symptoms with "band-aid" solutions; it aims for the underlying causes. This often entails challenging established institutions that control the distribution of resources and power. To be able to disrupt and change the broader system, "a social innovation must cross multiple social boundaries to reach more people and different people, more organizations and different organizations, organizations nested across scales (from local to regional to national to global) and linked in social networks" (Westley and Antadze 2010, 5).

Networks that only span between the private sector and the public sector will, consequently, not be sufficient to achieve real system transformation. Rather, collaboration between the establishment and radicals (Westley, Zimmerman, and Patton 2007) will be needed. The powerful established governance networks that often are seen as efficient and as having a strong "ability to act" will not necessarily be the solution, because social change can't be enforced from the top down; rather it is necessary to mobilize resources and create conditions for change to emerge (ibid.). Also, when aiming for social change it is crucial to put inquiry ahead of certitude and to allow paradoxes and multiple perspectives, because "there are no simple formulas-serious and significant social change necessarily involves recognizing and dealing with complex systems" (Westley, Zimmerman, and Patton 2007, ix). This calls for networks built on heterogeneity and explicit inclusion of smaller actors. One such network concept is "the bees and the trees," where the "bees" are bottom-up actors with ideas and the "trees" are top-down actors with resources and power:

Social change depends, in other words, on alliances between what could be called the "bees" and the "trees." The bees are the small organisations, individuals and groups who have the new ideas, and are mobile, quick and able to cross-pollinate. The trees are the big organisations-governments, companies or big NGOs-which are poor at creativity but generally good at implementation, and which have the resilience, roots and scale to make things happen. Both need each other, and most social change comes from alliances between the two, just as most change within organisations depends on alliances between leaders and groups well down the formal hierarchy. (Mulgan 2007, 20) 
Here it is relevant to highlight the importance of knowledge as a resource, and the need for different actors to collaborate and exchange different knowledge to be innovative-something that has been emphasized in recent innovation research (Lakhani and Panetta 2007; Lusch, Vargo, and Tanniru 2010). It is also important to emphasize that it's not only the "bees" that needs the resources of the "trees" but that the established and powerful actors also need the resources of weaker actors-the knowledge from the margins. Murray (2009) brings up the shift to a networked paradigm where distributed systems spread complexity from centralized organizations to the margins-to households and front-line workers. These actors at the margins could be seen as closely related to the "bees":

Those at the margins have what those at the center can never have-a knowledge of detail-the specificity of time, of place, of particular events, and in the consumer's and citizens case, of need and desire. This is the potential. But to realise it requires new terms of engagement with users, new relations at work, new terms of employment and compensation. (ibid., 19)

Westley and Antadze $(2010,5)$ also emphasize the importance of local contributions and viewpoints from marginalized actors: "[S]ocial innovation not only serves vulnerable populations, but is served by them in turn." With departure in these theoretical accounts, we think it is interesting to explore if participatory design and agonistic design things could be a suggestion for "new forms of participation"-new platforms for gathering heterogeneous stakeholders to deal consciously with societal challenges and social innovation.

\section{Participatory design and agonistic design things}

The question "Who should participate?" has always been central to participatory design. Participatory design has paid considerable attention to marginalized actors and power relations. However, when participatory design has moved from a strong focus on "workplace" controversies related to information technology and become more engaged in public spheres and everyday life, the range of who can participate in design processes has expanded. If the former focus was on a fixed user group within a workplace, it is now on heterogeneous and evolving networks that cut across organizational and community borders, very much in line with the kind of networks that social innovation researchers and practitioners, and now also the Malmö Commission, have requested.

This shift has also raised the question of what the central object of design should be. We have argued that it is more crucial to pay attention to designing things (sociomaterial assemblies) than "things" (objects) (Ehn 2008; Björgvinsson, Ehn, and Hillgren 2010, 2012a,b). The rationale behind this is that when you stage and set the scene of a development/design project (and what could become larger investments into a future change) it is critical to consider what human and non-human resources could be 
aligned. By "non-human resources" we mean artifacts, information, and design devices such as sketches and prototypes.

What makes the concept of design things relevant in a discussion about governance and social innovation is the original meaning of the word "Thing" in Nordic and Germanic societies: a governing assembly in which "disputes were solved and political decisions made" (Binder et al. 2011, 1). Thinking of design as assemblies in which heterogeneous actors are gathered into design things puts the focus on the diverse matters of concerns among the participating stakeholders. Still, it is not only the initial gathering of a broad spectrum of actors that discuss matters of concerns that makes a design thing relevant, but also how this discussion continues through collaborative experiments and prototypes (human and non-human) and where the design thing continuously could evolve and move the object of design forward. A design thing should be considered as a process that involves both setting the preconditions for a process of change and opening up opportunities for new design things in which future users and stakeholders can discuss new matters of concern according to changed conditions and re-design the outcomes of previous design things. In this process the design thing also makes the objects of design and the matters of concern public through workshops, exhibitions, public debates, blogs, and videos.

Another concept that has been explored within participatory design in recent years, and one that we believe could be valuable for governance and social innovation, is agonism (Björgvinsson, Ehn, and Hillgren 2010, 2012a; DiSalvo 2010, 2012). The concept was brought forward by the political scientist Chantal Mouffe (2000a,b) as a way to approach political hegemony. Marginal actors often are left outside political coalitions that build on consensus. Agonism is best understood in relation to antagonism (the struggle between enemies). Agonism is the struggle between adversaries. An adversary is "somebody whose ideas we combat but whose right to defend those ideas we do not put into question" (Mouffe 2000a, 15). For Mouffe (2000b), "agonistic struggle" is at the core of a vibrant democracy. Democracy should promote a multiplicity of voices, adversaries with opposing views debating matters of concern constructively and passionately. The aim should not be to reach consensus or to support rational decisionmaking processes, but rather to make the alternative views clearer and more visible.

Merging the concept of agonism and the concept of things highlights that it is important not only to assemble heterogeneous stakeholders who might aim for a shared vision and agree on a preferred solution, but also to bring out alternative opportunities and allow for a polyphony of voices and for mutually vigorous but tolerant disputes among these stakeholders.

With this as a background, we would argue that, whereas governance researchers have asked for new forms of participation, new inclusive arenas, and platforms (Stigendal 2011), participatory design and agonistic design things could be central elements in what could constitute a political arena. In this way we also position ourselves in 
relation to a view of social innovation that is more disruptive, focusing on politics and system change and "aiming to change power-relations, alter social hierarchies, and reframe issues to the benefit of otherwise disenfranchised groups" (Nicholls and Murdock 2012, 5). We will therefore return to the process of establishing the incubator for social innovation to see how such an agonistic design thing could emerge in practice.

\section{The incubator workshop as an agonistic design thing}

After the meeting in Malmö's city hall, Living Lab the Neighborhood was commissioned by the municipality to conduct three design workshops to explore how the incubator should be structured and how its functions should be designed to be able to support new initiatives in the city. We saw this as an opportunity to explore how an agonistic design thing could be set up. Although this specific case started with the commission, some crucial design work was conducted long before that, making it easier for us to mobilize relevant competences and stakeholders into the workshop process. When we engage in design research, our basic strategy is to go beyond a well-defined design project with pre-defined stakeholders, time lines, and goals. Rather, we aim for a process of infrastructuring, focusing on building long-term relationships with diverse stakeholders who have complementary competences. We also aim to work with constellations of actors that are more heterogeneous than the governance networks that usually are active in the political processes in Malmö. In the infrastructuring process, we explore how new opportunities for design interventions can emerge from matchmaking between stakeholder interests and resources (Björgvinsson, Ehn, and Hillgren 2010). Because we had been working with the infrastructuring process before the incubator discussions started, we had been engaged in many ways with NGOs, with social innovators, with small companies, and with civil servants. This involvement had helped us to get a sense of their capabilities and to build mutual trust. All these actors made up a network of potential participants in different design processes.

When choosing whom to invite to the workshops, our strategy was to start with six local initiatives consisting of associations or small companies that could act as potential users of services that the future incubator could provide. Some of them were well-established initiatives, such as Aluma, a magazine (now defunct) that was sold by homeless people; others were grassroots organizations, such as the multicultural Herrgård's Women's Association, whose members live and work in the margins but have strong networks and extensive knowledge and ideas about social change. Some started as grassroots initiatives but have been able to grow and become established as a part of the municipality, giving them experience of being both within and outside the more established institutions such as the Kaninhotellet (literally "Rabbit Hotel"), a youth center that also accommodates many small pets. Some have, through our previous design activities, gone into joint collaboration with each other, combining 
intercultural competences with new-media skills. (One example is Miljonprocessen, a joint business venture between a hip-hop community and a small ICT company.) We also invited Barn i stan (a project run by a Somali association that wanted to use urban farming to connect immigrant kids with Swedish seniors in one of Malmö's toughest areas) and Feed'us (a small group of young adults, tired of making trouble in the streets, who wanted to create a company based on recycling and to become positive role models for children and teenagers). All these stakeholders could be considered as "bees" that needed resources from the "trees," but they also possessed unique resources themselves. Most of them also had a lot of "intercultural competence" or other kinds of knowledge from the margins regarding issues like social exclusion, education, or homelessness, a kind of knowledge that the "trees" need to be able to create relevant change.

All the stakeholders mentioned above had been active in taking initiatives to achieve social change in their local environments and, as said, could be seen as potential users of the incubator. Based on the participatory design standpoint that "those affected by a design should have a say in the design process" (Binder et al. 2011, 162), but also to utilize their knowledge from the margins, we decided to set up a significant part of the workshop around their everyday practices, capabilities, and needs. As a complement, we recruited research colleagues with complementary knowledge, people from organizations supporting social entrepreneurial initiatives, traditional business developers, and civil servants representing different municipal departments. Together, the workshop participants represented a huge resource of complementary competence and perspectives, potentially with agonistic perspectives on what could be an incubator for social innovation.

\section{The workshops}

In the first workshop, the six initiatives presented their experiences and issues. Divided into smaller groups, the participants started mapping and discussing the challenges and opportunities of each initiative, trying to identify issues that the future incubator would be able to deal with. In the second workshop, the participants departed from the challenges of the different initiatives and focused on identifying support functions of the incubator and how it could relate to other organizations and society as a whole. Questions regarding trust, ownership, financing, criteria for evaluating ideas, and other matters emerged. The third and last workshop created four scenarios for how the incubator could work.

In the first scenario the concept of a "free zone" was important, and "intermediaries" that could spot ideas and translate dreams into a language that could be accepted by bureaucracy played the most central role. The second scenario was an incubator that was run by the actors that were already active in social innovation and could move around in the city. Here too the idea of a "free zone" was important, and it was suggested that different initiatives should be judged by "crowd judging." The third 


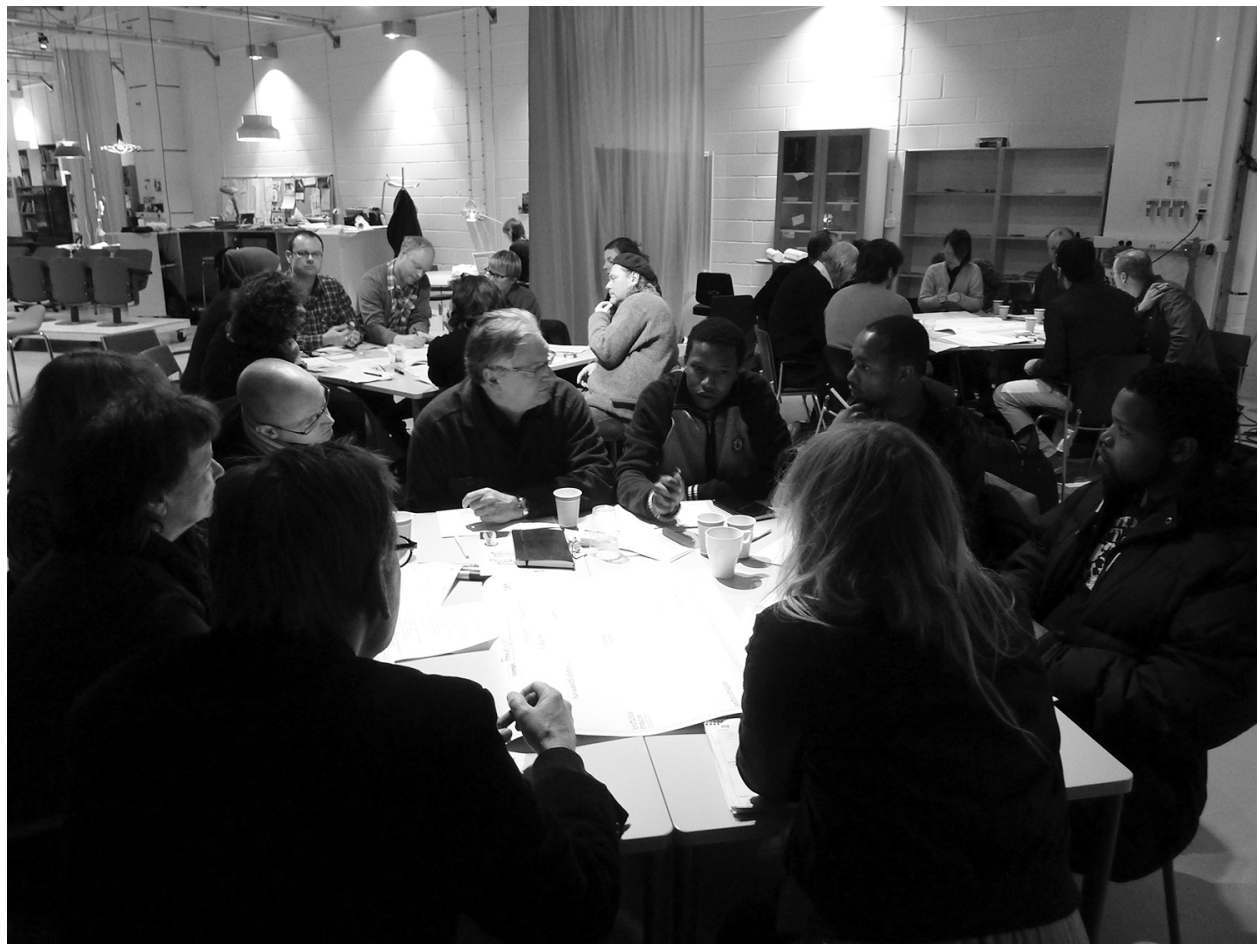

Figure 4.1

The participants gathered in a design thing during the workshops at the university.

scenario was a decentralized incubator with a pool of resources. Here the emphases were on the importance of the local context and on the idea that initiatives should be developed locally. The incubator, it was suggested, should work as a test bed, and the issue of power balance was brought up; the consensus was that the social innovators should have as much power as the "big elephants" (municipality, academia, trade, industry). The fourth scenario emphasized that different initiatives need different kinds of support and therefore had to enter into the incubator at different levels. Here too the idea of a "free zone" was emphasized.

\section{Outcomes of the workshops}

The breadth and the diversity of the stakeholders was evident in the outcomes of the workshops, which we present below in four recurring categories.

Ownership and mandate The general view was that not only the municipality should own and run the incubator but that also the actors active in social innovation should 
take part in running the incubator. The participants clearly expressed their will to take part in the following process of creating and building the incubator and that "we as builders need to be the owners." They also pointed out that the incubator needed to have a "mandate" from those actors who are active within social innovation in Malmö today. That message was repeated in our report (Ehn et al. 2011).

Mental free zone It was agreed that the incubator should be a place where civil servants and social innovators could shift roles, or work in a different mode than they do on an everyday basis; to create a "mental free zone." We would argue that this came about because of the mix of stakeholders and perspectives that were represented in the workshops. A free zone was also discussed in the sense of a safe place to experiment with ideas and challenge economical and juridical frames.

Centralized vs. distributed One of the more interesting outcomes had to do with the set-up and location of the incubator. Traditionally an incubator is viewed as a specific space with staff-members such as business developers and coordinators that support new business initiatives. During the workshops, that structure was questioned. The majority favored a more distributed model, building on existing resources, such as an organization, a company, or a local municipality office that already provided support services, and locating activities in different districts of the city. In the final report, we discussed two contrasting models - the central incubator and the decentralized incubator-and showed how they could fit into the wider social innovation landscape of Malmö. We thought it was important to not only focus on the incubator as such but to try to take a systemic view by embracing the whole chain of innovation. (See figure 4.2.)

Mutual learning process At first many criticisms of the municipality and civil servants were voiced, but quite soon the discussion came to focus on the importance of establishing mutual learning between the stakeholders-between different departments within the municipality as well as between civil servants, citizens, and NGOs. Some self-criticism also was voiced, and one representative of the third sector expressed the opinion that also they needed to renew themselves. The "free zone" was mentioned as a place for mutual learning.

Matchmaking Our initial infrastructuring of the workshop process, in which we aimed for a mix of organizations and competences, created immediate results during the workshops. We could see how different constellations were starting to emerge: the magazine Aluma began to negotiate with the interaction design company Do-Fi on how to deal with money transactions in a cashless society, the ideation bureau Artcom helped Feed'us to write a business plan, and the Swedish Red Cross also started a conversation with Feed'us. 


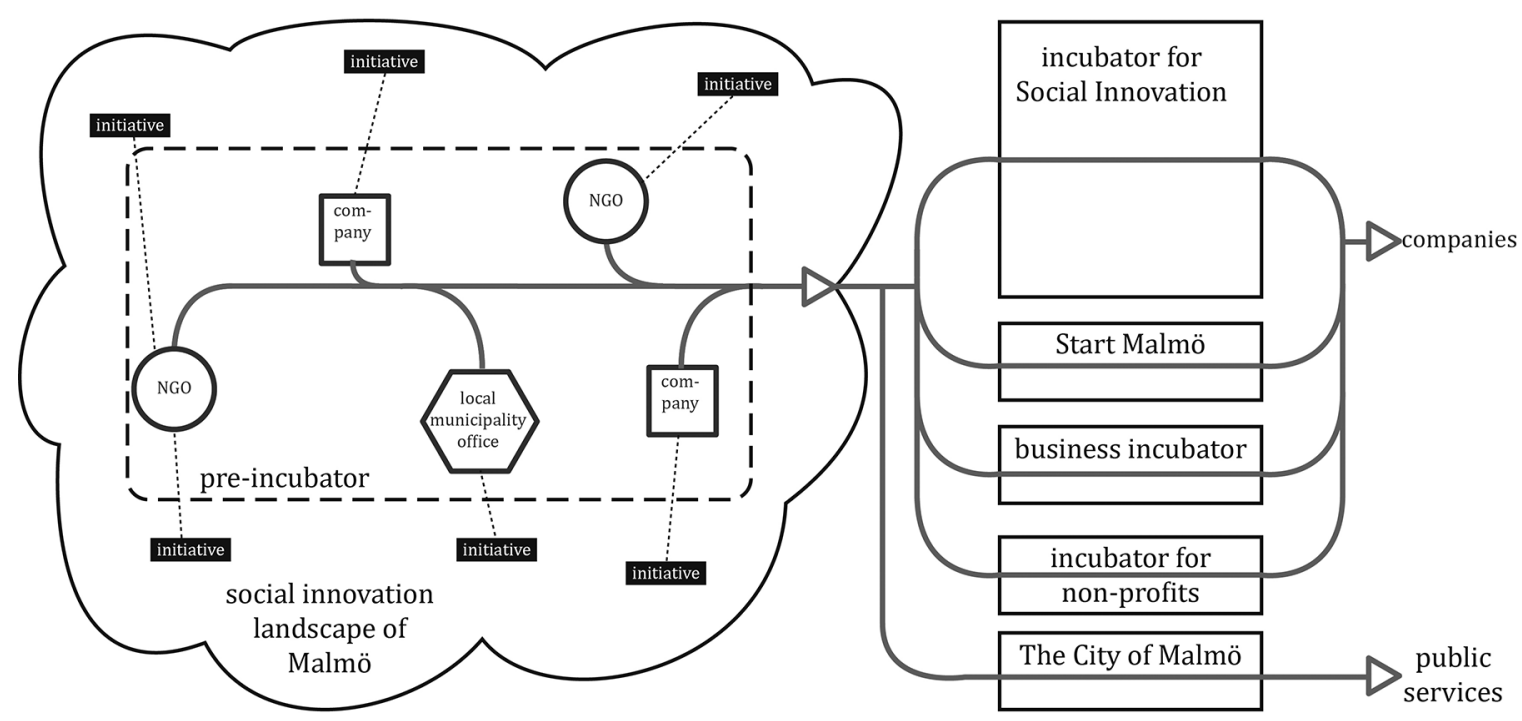

Figure 4.2

The distributed incubator model that emerged during the workshops was transformed into a new model with both a traditional incubator and a distributed pre-incubator. The pre-incubator built on existing resources in the wider social innovation landscape of Malmö, such as a company, an NGO, or a local municipality office that already provided support services. The idea was that the pre-incubator could channel more mature business initiatives to Start Malmö and other established business incubators. However, it would also have the capacity to support initiatives that were far from having traditional business opportunities, but with a potential to create value for society in the form of an association or developing into a public service.

\section{From agonistic design thing to governance by "powerful strangers"}

After the three workshops, we summed up the results and had a meeting with the civil servant responsible for the incubator process and the civil servant responsible for writing the official report that would be the basis for further decisions in the City Council. They couldn't really accept the distributed incubator model, to some degree because they could see how hard it would be to get support for such a model in the City Council. However, they realized that a traditional central incubator would need ideas and initiatives coming from the city areas with social challenges, and that, because of the need to mobilize, use, and support existing grassroots resources, it was necessary to consider the whole chain of innovation. During the meeting, these considerations opened up the possibility of a creative act of "bureaucratic translation." The distributed 
incubator model was transformed into a new model consisting of both a traditional incubator and a pre-incubator, in which the setup of the pre-incubator was based on findings from the workshops. The bureaucratic skills of the civil servants made it possible to translate the workshop findings into a document that presented something new (and slightly radical), but which was still within the City Council's "safe zone." So far, the design thing was still alive.

In a way, the bureaucratic translation continued in the more closed process at the Trade and Industry Agency. Now there were only a few actors, most of them with a business perspective. The exception was the civil servant responsible for the Area Programs, who had come up with the idea of establishing an incubator for social innovation. With the exceptions of that civil servant, the one from the Trade and Industry Agency responsible for the incubator process, and our business developer, the other actors hadn't participated in the workshops, even though some of them had been invited. From here on, these actors will be characterized as powerful strangers.

The concept of the powerful stranger is brought forward by Westley, Zimmerman, and Patton $(2007,95)$, who see power as control of resources ("time, energy, money, talent and social connections") that creating something new requires. Power also means the power to maintain the status quo or the power to change it. Anyone who wish to transform a system has to unlock resources claimed by the status quo. Therefore, a change maker that lacks resources should embrace "the risk and rewards of engaging the powerful stranger":

Early power and resources for change are often found through connecting, through joining together with fellow travellers, like-minded individuals whose chief resources are their passion, their time and their energy. If successful at this stage, the community becomes a movement, which opens the door for confrontation and possibly conflict as those who control larger portions of money, authority and access resist demands for change. If the system is to be transformed as opposed to overturned, collaboration between the radicals and the establishment must be created. If it succeeds, deep shifts in the distribution of resources may occur. (ibid., 99)

The actors in the trade and industry network are powerful in the sense that "they control larger portions of money, authority and access" (Westley, Zimmerman, and Patton, 2007, 99) and are strangers in the sense that they never connected, confronted, or collaborated with the other stakeholders during the workshops. Instead they exercised their power hidden and at a distance from the most important stakeholdersthe potential social innovators, entrepreneurs, and front-line workers with knowledge from the margins-the actors the social incubator was originally intended for. The powerful strangers never took part in mutual learning with the other stakeholders.

The trade and industry network prepared a document that included quite a few of the outcomes from the workshops but focused mainly on new jobs. The politicians rejected that document because they didn't understand social innovation. "Some politicians," one civil servant commented, "didn't understand the concepts of social 
innovation and social entrepreneurship: 'You should not fiddle with the municipal competence.'" "To work with an assignment that is the municipality's by law," the civil servant continued, "that's holy, you can't touch that."

The participants had to compromise. They took out all the sentences that mentioned social innovation, and added, as the aforementioned civil servant put it, that the "activities should not be aimed at assignments that belongs to the municipality by law." Later it became evident that the civil servants who became intermediaries between the design thing and the trade and industry network had struggled with defending the core statements relating to social innovation in the document. One civil servant thought that the participants had gone too far and suggested returning to the original focus on an incubator for social innovation. Again there was a need for "bureaucratic translation" and rewriting, and the result was a compromise. The headline of the new text was now "The establishment of an incubator for entrepreneurs with a focus on social innovations" (Spjut 2011). In the first sentence, that was changed to "an incubator for new jobs and innovation," and that wording dominated the rest of the text. But if one read between the lines, the main message from the workshops-that is, the idea of a local pre-incubator system that could complement a central incubator-was still there. The mentioning of an "innovation system" that could work on two levels was also important. But the most important actors working on the local level-grassroots organizations, non-profit organizations, and NGOs-weren't represented in the trade and industry network that had the power to decide what would become the final decision document and they were mentioned only briefly in the document. From the perspective of participatory design and the wish to create a new innovation system to tackle social challenges, the absence of third-sector representatives and the other "bees" was devastating.

Because we arranged the workshops as a design thing, we wanted there to be a democratic process in which heterogeneous actors could take part. In the first phase of the incubator process (the workshops at the university) we were quite successful in this, but when the invited powerful actors from the trade and industry and the municipality were absent the perspective of the public and that of the third sector dominated. Although we had a very good precondition for a design thing, by losing these powerful actors we also lost some of the expected agonistic struggle and mutual learning. When the powerful strangers took a more active role in the second phase of the incubator process and the actors who should have been preparing a decision document for the politicians narrowed down significantly, the design thing began to fall apart. From that moment on, the incubator was in the hands of a small and elite group consisting mainly of people with a trade and industry perspective-representatives of the established governance networks. We were back to "business as usual." 


\section{Discussion}

In this chapter we have analyzed the process of exploring what an incubator for social innovation could be. The idea of a social incubator came from a civil servant responsible for the Area Programs who saw the need of a clearer structure for innovative work. However, the outcome of the incubator process was not an incubator for social innovation; it was an organization called Growth Malmö that focuses on supporting existing companies that want to hire more employees. Some of the companies they support are claimed to be social entrepreneurs. In August of 2013, Growth Malmö reported to have contributed to the creation of 1,000 new jobs. Again the governance networks had demonstrated their efficiency and ability to act. Of course, the creation of new jobs is an important contribution to the advancement of welfare and social sustainability in Malmö. But at what cost?

Malmö lost an emerging "knowledge alliance" concerned with supporting social innovation. It also lost a more holistic view of such an innovation system. In the incubator report (Ehn et al. 2011) we sketched an innovation system with many different actors, including the mother organization of Growth Malmö-Start Malmö. But with the establishment of Growth Malmö it seemed that the City of Malmö was satisfied.

The moment the politicians decided to accept the proposal from the trade and industry network, the design thing at the university dissolved and the actors that had been mobilized scattered, going off to work by themselves, and their ability to act with a common purpose became neutralized. Also lost was an emerging new democratic platform-something that, together with knowledge alliances, the Malmö Commission would later emphasize as important in creating social sustainability along with new jobs. We will therefore now discuss why knowledge alliances and new democratic platforms are needed.

In trying to understand what happened when the object of design (the issue of the incubator) traveled from the design thing at the university to the governance network at the Trade and Industry Agency, we could observe both a lack of accountability and the exclusivity of small informal networks. As was mentioned earlier, both of these factors have been brought up as major drawbacks by governance researchers who argue that they may threaten democracy (Dannestam 2009; Stoker 2000). Swyngedouw $(2005,1999)$, who points to the tension between the possibilities of increased democratization through participatory governance and the fact that these governance networks are often led by "coalitions of economic, socio-cultural or political élites," states that governance has "undoubtedly given a greater voice and power to some organizations (of a particular kind-i.e. those who accept playing according to the rules set from within the leading élite networks)." "However," he continues, "it has also consolidated 
and enhanced the power of groups associated with the drive toward marketisation and has diminished the participatory status of groups associated with social-democratic or anti-privatisation strategies" (ibid., 2003). Stigendal (2011, 31; translated from Swedish) also argues that this exclusiveness raises questions about democracy because governance often involves trade and industry but not "the third sector or representatives of people with low participation in elections," the same group that was excluded in the second phase of the incubator process. Stigendal (2012; translated from Swedish) means that a return to traditional hierarchical government is not a solution; instead, more actors and stakeholders should be able to participate in these networks-a sort of "governance with all." The incubator workshops—-the design thing-could be seen as an attempt to experiment with doing "governance with all," even if 100 percent inclusion is impossible.

As has been said, the focus on creating employment is, of course, relevant to tackling the social challenges facing Malmö. But to highlight only the creation of new jobs is to risk losing sight of the fact that the conditions for creating new jobs, and social sustainability, depend on many interconnected factors-for example, education, distribution of resources, and how public services work. This complexity was evident in discussions during the workshops and in the Area Programs' deciding to focus on both new jobs and education.

The importance of taking a holistic perspective and that of merging different kinds of knowledge so as to be able to tackle complex societal challenges was also emphasized in the final report of the Malmö Commission (Stigendal and Östergren 2013). The commission recommended that new processes of change be based on knowledge alliances and on more democratized governance. It also recommended a change from an emphasis on conditions and results to an emphasis on continuous knowledge and learning processes-a change that would not be about identifying and solving single problems but instead would depart from a holistic perspective and try to solve many problems simultaneously. This, in turn, requires more open processes in which a departure point or a problem is identified by a circle of stakeholders wider than a traditional one. The commission also asserts that in this new processes it is less important to have a final goal clearly defined than to have a direction that allows the exploration of new solutions and the development of new knowledge. Keywords for this new kind of change processes include "creation of new knowledge," "participation," and "system change." One of the gains to be achieved by involving citizens is that a knowledge alliance gets access to both formal and informal knowledge, and in this context the commission mentions the "intercultural competence" that many citizens of Malmö possess.

In regard to social complexity and the idea that social sustainability isn't limited to jobs and companies, it is crucial to bring up the partly unnoticed but important work of the third sector, both in education and in creating a feeling of belonging for many marginalized citizens. This became clear during the workshops. One theme that emerged during the workshops was "people's movement 2.0," which highlighted that 
some present-day grassroots organizations and youth organizations are organized in a new way, not yet acknowledged, that falls between established categorizations and departments. One consequence of this is that it is difficult for such organizations to get financial support. But they do a lot of important work for society, for example with education. The representative from Miljonprocessen, who also is the leader of the youth organization RGRA, brought up this issue. Two years later this issue was emphasized by Sernhede and Söderman (2013), who noted the importance of this new kind of people's movement, and that of organizations such as RGRA in Malmö, Megafonen in Husby/Stockholm, and Pantrarna in Gothenburg in relation to the 2013 riots in Husby/Stockholm.

Stigendal and Östergren (2013) argue that one explanation for why the situation in Malmö isn't even worse is that the work done by cultural and third-sector organizations is having a positive influence on people's health, their feeling of participation in society, and the creation of trust between people. They also consider the possibility that the third sector has a great potential for creating social sustainability and therefore "should be taken into consideration in many of the political decisions that aim at making the city socially sustainable" (ibid., 48; translated from Swedish). But "people's movement 2.0" and other issues that concerned the third sector would not be a concern or a task of the future incubator as it was further developed by the powerful strangers that dominated the process after the workshops.

Although the politics of Malmö still emphasize economic growth, alternative perspectives seem to emerge from the Malmö Commission. It has to be acknowledged that the small informal governance networks with a strong ability to act have been taking several initiatives that are seen as successful by the majority of citizens (for example, starting the university, initiating the bridge, and the city district known as the Western Harbor). But, as has been argued by many researchers, something else is needed when dealing with complex social issues. The challenge here seems to be how to balance the ability to embrace complexity with the ability to act-how to tackle complex challenges without reducing them to single issues and excluding important actors. This challenge is addressed by Huppé, Creech, and Knoblauch (2012), who argue that governance networks that deal with sustainable development should address the connections between the economy, society, and the natural environment and should try to avoid fragmentation and institutions based on single issues. According to them, these networks will need participants from all sectors from society, including the business sector and the third sector. However, this may create an efficacy paradox: heterogeneity and complex networks may reduce the effectiveness of the process and the ability of participants to reach common goals. The solution suggested by Huppé et al. is to combine processes of opening up the network with processes of closing down the network, in order to avoid paralysis and maintain a strong ability to act and make decisions. Huppé et al. also emphasize the importance in these networks of reflexive learning, whereby stakeholders gain understanding of each other's respective positions and trust 
and social capital can grow through common activities-something that also was highlighted during the incubator workshops.

\section{Powerful strangers and political design}

We started this story with our meeting with one "powerful stranger" in the corridors of Malmö's city hall. This is the usual arena for elite actors and members of the informal governance networks - the corridors of power and boardrooms - and not the kind of inclusive and democratic platform that was our goal in setting up the design thing at the university. The workshops at the university, taking the form of a "design thing", could be seen as an attempt to set up the conditions for connection, confrontation, and collaboration between "the radicals and the establishment." But the powerful actors never turned up. The design thing fell apart, and most participants were excluded from the decision-making phase. However, we would argue that this breakdown explicitly puts the focus on the need for new inclusive governance forms. As we have tried to argue in this chapter, we believe that participatory design and agonistic design things could contribute to the building of democratic governance networks that would be able to tackle complexity and to address issues of sustainability.

To bring design into the political sphere may seem awkward. However, it has long been argued that design is an approach that is well suited to dealing with complexity and with wicked problems (Rittel and Webber 1973). In recent years, design, and specifically design thinking, has gotten a lot of attention as an approach that could contribute fruitfully to governance and to policy development in the public sector (Bason 2010; Christiansen and Bunt 2012; Jégou et al. 2013). Although design approaches have been embraced by many in the public sector, design's practical influence on public policy is still modest. According to Christiansen and Bunt, one reasons for this is that design approaches involve experimentation, which involves the possibility of risk and which for that reason is viewed as less accountable than known bureaucratic procedures with predictable outcomes. Christiansen and Bunt $(2012,18)$ instead suggest that "informed experimentation" can be seen as "the responsible foundation for decision making in complex settings."

However, it is not only how civil servants set up their everyday work that is challenged. Several researchers rooted in participatory design have, in line with what we are proposing here, argued that design should take a further step into the political (Botero and Saad-Sulonen 2013; Staszowski, Brown, and Winter 2013). Here it is relevant to consider the distinction between what DiSalvo (2010) calls design for politics, with its focus on "improving structures and mechanisms that enable governing", and political design, which is more focused on revealing and confronting power relations and on identifying "new terms and themes for contestation and new trajectories for action." (ibid., no paging) 
DiSalvo (2010) has reviewed some "design for democracy" projects and found that most fit into the established realm of politics. Here DiSalvo is referring mostly to American projects that work as "design applied to politics" or "design for politics"; however, service-design projects in the United Kingdom, where designers are helping to implement the government's Big Society policy and "are already facilitating social innovations that can replace government services" (Tonkinwise 2010, no paging), could be added to this category. As DiSalvo (2010, no paging) notes, these projects are not "political in an agonistic sense" and "do not represent the range of possible thought and action available to design within the democratic endeavour." According to DiSalvo, an agonistic approach could ask questions and reveal and confront power relations.

The process with the incubator that we have outlined in this chapter brings this view on design up front, especially in regard to the report of the Malmö Commission and the perspectives that the political scientist Tove Dannestam and the sociologist Mikael Stigendal bring to the situation in Malmö.

A design thing can contribute to democratic governance processes by widening the networks and by paying attention to who is included. A design thing explicitly tries to include marginalized and opposing actors and to connect them with stronger more resourceful stakeholders (that is, to connect the "bees" and the "trees"). Also, through a design thing, pre-defined projects are not imposed on other people, and most of the important agendas haven't already been set. Rather, a constellation of diverse stakeholders is assembled to elaborate what could become a future project and what matters of concern that should be elaborated further. A design thing doesn't stop with a group of people and a decision at the workshop table, either. Often it moves beyond producing ideas and deciding which of them to implement, and through phases of collaborative experimentation it explores how diverse ideas can be situated and made sense of. A design thing not only assembles diverse people but also assembles diverse artifacts, prototypes, processes, and sketches to perform collaborative explorations of matters of concern and alternative futures (Björgvinsson, Ehn, and Hillgren 2010, 2012a). During these processes, reports, sketches, and videos are made public-something that is crucial for accountability, and something that is seldom encountered in traditional governance networks.

Our aim was to set up design things in agonistic formats so that disagreements could spur vivid discussions without definitively leading to consensus. That was why we invited people we knew would have very opposing views as to what should constitute an incubator or what was needed to tackle some of the challenges that face Malmö today. However when several of the powerful strangers opted out we also lost some of the agonistic battle that we believe should have produced valuable knowledge about this issue.

We are certainly not against a concrete result such as 1,000 new jobs, but we think such a result is problematic when it is created in the absence of other voices and 
opinions, continuous inquiries, and the creation of new knowledge. We need both a capacity to act and knowledge about what to act upon. A majority of the research on such knowledge creation points in the direction of diverse constellations such as knowledge alliances and design things rather than in the direction of single-issueoriented governance networks. The ability to act and to achieve results quickly should be complemented by long-term learning and by experimental processes that embrace complexity and address societal challenges on a systemic level. That is a good reason to continue to explore the potential of design things for becoming a new democratic platform for "governance with all."

\section{References}

Bason, C. 2010. Leading Public Sector Innovation: Co-creating for a Better Society. Policy Press.

Binder, Thomas, Giorgio De Michelis, Pelle Ehn, Giulio Jacucci, Per Linde, and Ina Wagner. 2011. Design Things. MIT Press.

Björgvinsson, Erling, Pelle Ehn, and Per-Anders Hillgren. 2010. Participatory Design and "Democratizing Innovation." In Proceedings of the Eleventh Participatory Design Conference, Sydney.

Björgvinsson, Erling, Pelle Ehn and Per-Anders Hillgren. 2012a. Agonistic Participatory Design: Working with Marginalised Social Movements. CoDesign 8 (2-3): 127-144.

Björgvinsson, Erling, Pelle Ehn, and Per-Anders Hillgren. 2012b. Design Things and Design Thinking: Contemporary Participatory Design Challenges. Design Issues 28 (3): 101-116.

Blyth, Simon, and Lucy Kimbell. 2011. Design Thinking and the Big Society: From Solving Personal Troubles to Designing Social Problems. Actant and Taylor Haig.

Botero, Andrea, and Joanna Saad-Sulonen. 2013. Peer-Production in Public Services: Emerging Themes for Design Research and Action. In Public and Collaborative: Exploring the Intersection Of Design, Social Innovation and Public Policy, ed. E. Manzini and E. Staszowski. DESIS Network.

Christiansen, Jesper, and Laura Bunt. 2012. Innovation in Policy: Allowing for Creativity, Social Complexity and Uncertainty in Public Governance (http://www.nesta.org.uk)/publications/ assets/features/innovation_in_policy).

Dannestam, Tove. 2009. Stadspolitik i Malmö: Politikens meningsskapande och materialitet. Lund Political Studies 155. Lunds Universitet.

DiSalvo, Carl. 2010. Design, Democracy and Agonistic Pluralism. In Proceedings of Design Research Society International Conference, Montreal (http://www.designresearchsociety.org/ docs-procs/DRS2010).

DiSalvo, Carl. 2012. Adversarial Design. MIT Press.

Ehn, Pelle. 2008. Participation in Design Things. In Proceedings of Participatory Design Conference, Bloomington, Indiana. 
Ehn, Pelle, Anders Emilson, Per-Anders Hillgren, and Anna Seravalli. 2011. Inkubatorn finns därute! (http://medea.mah.se/2011/05/inkubatorn-finns-darute).

Huppé, Gabriel A., Heather Creech, and Doris Knoblauch. 2012. The Frontiers of Networked Governance (www.iisd.org/pdf/2012/frontiers_networked_gov.pdf).

Jégou, François, Stéphane Vincent, Romain Thévenet, and Anna Lochard. 2013. Friendly Hacking into the Public Sector: Co-Creating Public Policies within Regional Governments. Presented at Boundary-Crossing Conference on Co-Design in Innovation, Aalto University (http://www. slideshare.net/27eregion/friendly-hacking-into-public-sector).

Lakhani, Karim R., and Jill A. Panetta, J. 2007. The Principles of Distributed Innovation. Innovations 2 (3): 97-112.

Lusch, Robert F., Stephen L. Vargo, and Mohan Tanniru. 2010. Service, Value Networks and Learning. Journal of the Academy of Marketing Science 38: 19-31.

Mouffe, Chantal. 2000a. Deliberative Democracy or Agonistic Pluralism. Department of Political Science, Institute for Advanced Studies, Vienna.

Mouffe, Chantal. 2000b. The Democratic Paradox. Verso.

Mulgan, Geoff. 2007. Social Innovation: What It Is, Why It Matters and How It Can Be Accelerated. Saïd Business School, Oxford University.

Mulgan, Geoff. 2012. The Theoretical Foundations of Social Innovation. In Social innovation: Blurring Boundaries to Reconfigure Markets, ed. A. Nicholls and A. Murdock. Palgrave Macmillan.

Murray, Robin. 2009. Danger and Opportunity: Crisis and the New Social Economy. Nesta.

Murray, Robin, Julie Caulier-Grice, and Geoff Mulgan. 2010. The Open Book of Social Innovation. Young Foundation, Nesta.

Nicholls, Alex, and Alexander Murdock, eds. 2012. Social Innovation: Blurring Boundaries to Reconfigure Markets. Palgrave Macmillan.

Pierre, J., and Peters, G. B. 2000. Governance, Politics and the State. Macmillan.

Rhodes, R. A. W. 1997. Understanding Governance: Policy, Networks, Governance, Reflexivity and Accountability. Open University Press.

Rittel, H. W., and M. M. Webber. 1973. Dilemmas in a General Theory of Planning. Policy Sciences 4 (2): $155-169$.

Sernhede, Ove, and Johan Söderman. 2013. Kur mot kravaller. Sydsvenska Dagbladet, May 24 (http://www.sydsvenskan.se/kultur--nojen/kur-mot-kravaller/).

Spjut, Anders. 2011. Inrättande av en inkubator för entreprenörer med inriktning på sociala innovationer. Stadskontoret, Malmö stad.

Staszowski, E., S. Brown, and B. Winter. 2013. Reflections on Designing for Social Innovation in the Public Sector: A case study in New York City. In Public and Collaborative: Exploring the 
Intersection Of Design, Social Innovation and Public Policy, ed. E. Manzini and E. Staszowski. DESIS Network.

Stigendal, Mikael., 2011. Malmö—de två kunskapsstäderna. Kommission för ett socialt hållbart Malmö.

Stigendal, Mikael. 2012. Malmö-de två kunskapsstäderna (http://www.youtube.com/ watch?v=gk3SRO1XqXY).

Stigendal, Mikael, and Per-Olof Östergren. 2013. Malmös väg mot en hållbar framtid. Hälsa, Välfärd och rättvisa. Kommision för ett socialt hållbart Malmö.

Stoker, Gerry. 2000. Urban Political Science and the Challenge of Urban Governance. In Debating Governance, ed. J. Pierre. Oxford University Press.

Swyngedouw, Erik. 2005. Governance Innovation and the Citizen: The Janus Face of Governancebeyond-the-State. Urban Studies 42 (11): 1991-2006.

Tonkinwise, Cameron. 2010. Politics Please, We're Social Designers (http://www.core77.com/ blog/featured_items/politics_please_were_social_designers_by_cameron_tonkinwise_17284.asp).

Westley, Frances, Brenda Zimmerman, and Michael Quinn Patton. 2007. Getting to Maybe: How the World Is Changed. Vintage Canada.

Westley, Frances, and Nino Antadze. 2010. Making a Difference: Strategies for Scaling Social Innovation for Greater Impact. Innovation Journal 15 (2): 3-20. 